\title{
A nudibranch removes rival sperm with a disposable spiny penis
}

\author{
Ayami Sekizawa $^{1,2} \cdot$ Shin G. Goto ${ }^{1}$ Y Yasuhiro Nakashima ${ }^{3}$
}

Received: 23 January 2018 / Accepted: 21 September 2018 / Published online: 27 October 2018

(c) The Author(s) 2019, corrected publication 2019

\begin{abstract}
Simultaneous hermaphroditism is, at least initially, favoured by selection under low density — and therefore it can be assumed that sperm competition has little importance in this sexual system. However, many simultaneously hermaphroditic nudibranchs have both an allo-sperm storage organ (the seminal receptacle) and an allo-sperm digesting organ (the copulatory bursa), suggesting the possibility of the occurrence of sperm competition. A nudibranch, Chromodoris reticulata, autotomizes its penis after every copulation and replenishes it within about $24 \mathrm{~h}$ to perform another copulation. We observed that the surface of the autotomized penis was covered with many backward-pointing spines and that a sperm mass was often entangled on the spines. This suggests that the nudibranch removes sperm that is already stored in a mating partner's sperm storage organ(s) with its thorny penis. Using six microsatellite markers, we determined that the sperm mass attached to the penis were allo-sperm originating from individual(s) that had participated in prior copulations. We revealed that $C$. reticulata performed sperm removal using the thorny penis. These results suggest that competition in fertilization is quite intense and mating frequency in the wild is relatively high in this species.
\end{abstract}

Keywords Sexual selection $\cdot$ Sperm removal $\cdot$ Sperm competition $\cdot$ Nudibranch $\cdot$ Simultaneous hermaphrodite

\section{Introduction}

It was originally thought that simultaneous hermaphroditism was favoured by selection under low density, such as in deep-sea fishes, or low mobility, such as snails, and that sperm competition had little importance in simultaneous hermaphrodites (Ghiselin 1969). However, some simultaneous hermaphrodites are known to live in high density populations and show complicated mating behaviour (Fischer 1980, 1981: egg trading in hamlets; Leonard et al. 2007 : phally polymorphism in banana slugs). Moreover, multiple paternity was confirmed in some simultaneously hermaphroditic molluscs (Baur 1994; Angeloni et al. 2003; Evanno

Ayami Sekizawa

aym-ca15@hotmail.co.jp

1 Department of Biology and Geosciences, Graduate School of Science, Osaka City University, 3-3-138 Sugimoto Sumiyoshi-ku, Osaka-shi, Osaka 558-8585, Japan

2 Present Address: Graduate School of Agricultural Science, Tohoku University, 468-1 Aramaki Aza Aoba, Aoba-ku, Sendai 980-0845, Japan

3 Nihon University, College of Economics, 3-2-1 Kanda-Misakicho, Chiyoda-ku, Tokyo 101-8360, Japan et al. 2005; Kupfernagel et al. 2010), suggesting that sperm competition occurred in these hermaphroditic animals. These findings indicate that sexual selection functions in simultaneous hermaphrodites as strongly as in gonochorists, if not more strongly. Furthermore, mating behaviours, such as penis fencing in flatworms (Michiels and Newman 1998), cephalo-traumatic secretion transfer in head-shielded slugs (Lange et al. 2013, 2014), and disposable penises in nudibranchs (Sekizawa et al. 2013), show that some simultaneous hermaphrodites undergo severe competition to acquire the chance to inseminate, and suggest that they expose themselves to sperm competition. Additionally, some simultaneously hermaphroditic invertebrates have an organ(s) to digest and absorb sperm received from mating partners (Baur 1998; Michiels 1998). Together, these characteristics indicate the existence of intense sperm competition among simultaneous hermaphrodites as well as in gonochorists.

All nudibranchs are simultaneous hermaphrodites. During mating, they simultaneously play "male roles" as sperm donors and "female roles" as sperm recipients, in principle. The morphology of their female reproductive system is complicated, with two sperm storage organs, the copulatory bursa and the seminal receptacle. Hermaphroditic gastropods are generally thought to be able to digest allo-sperm 
stored in the copulatory bursae (Brandriff and Beemen 1973; Dillen et al. 2009; Lind 1973). The morphology, arrangement, and connectivity of the copulatory bursa and seminal receptacle are highly variable among nudibranch species (Rudman 1984; Valdés et al. 2010). This rich diversity in female reproductive systems implies that mating strategies vary among species and intense sexual selection operates, for example, in the form of sperm competition. Although reproductive system morphology is relatively well studied in nudibranchs, the function of each reproductive organ is not entirely clear. Additionally, direct evidence of sperm competition has not yet been obtained in nudibranchs (Baur 1998).

Chromodoris reticulata is reported to autotomize its penis after every copulation and replenish it within about $24 \mathrm{~h}$ in order to perform another copulation (Sekizawa et al. 2013). The fact that this nudibranch has a mechanism to repeat copulation within a short period of time with disposable penises indicates their high mating frequency. The autotomized penis is covered with many backward-pointing spines on its surface. It is known that simultaneously hermaphroditic nudibranchs have a wide variety of penis morphologies, including hooks at the tip and spines on the surface (Valdés et al. 2010). These hooks and spines are supposed to provide anchorage to prevent the penis from being unplugged from the mating partner during copulation (Valdés et al. 2010). However, the exact function of these projections on the penis has not been understood. Since a sperm mass was often entangled in the spines on the surface of an autotomized penis after copulation in C. reticulata (Sekizawa et al. 2013), this nudibranch has been proposed to scrape out allo-sperm already stored in the allo-sperm storage organ(s) of the mating partner with its thorny penis.

The genetic diversity of stored sperm in female sperm storage organs (Siva-Jothy and Hooper 1995), multiple paternity of a clutch of offspring, and last male precedence in reproductive success (Cooper et al. 1996) have been studied in insects using DNA analysis. These results suggest many insects perform sperm displacement by sperm removal (Córdoba-Aguilar et al. 2003; Kamimura 2000, 2003). Furthermore, Takami (2007) showed that spermatophore displacement was highly probable by DNA analysis of a spermatophore placed in the female genitalia of a ground beetle. However, verification of sperm removal by DNA analysis of scraped out sperm has never been carried out in any animal to our best knowledge, including gastropods and the wellstudied damselflies.

In this study, we clarified, by DNA analysis using microsatellite markers, that the sperm mass attached to the autotomized penis in C. reticulata originated, at least in part, from allo-sperm removed from the copulatory pouch(es) of the sperm recipient, and certified that the nudibranch performed sperm removal. We compared the traits and mechanisms of sperm displacement in this nudibranch to those of previous studies in insects. Subsequently, this showed direct evidence of sperm competition by sperm removal. We propose that sexual selection in this simultaneously hermaphroditic nudibranch functions as strongly as that in gonochorists.

\section{Materials and methods}

\section{Study animals}

The study animal, C. reticulata (Quoy and Gaimard 1832) (Opisthobranchia, Nudibranchia, Chromodoridae), is distributed in the Indo-West Pacific. In Japan, $C$. reticulata occurs on the rocky coast from central to southern Honshu and around the Ryukyu Islands. This nudibranch has a reticulated network of red lines over the surface of its mantle, reaches a length of $60 \mathrm{~mm}$, and feeds on sponges (Gosliner et al. 2008). The reproductive season of this species ranges from spring to early summer, and individuals spawn ribbon-shaped, yellow egg masses. As is typical of most opisthobranchs (Baur 1998), C. reticulata is a non-selfing, simultaneously hermaphroditic nudibranch. The allo-sperm received from the mating partner is stored in the copulatory bursa and seminal receptacle (Rudman 1984). C. reticulata exchanges sperm reciprocally during copulation in principle.

\section{Collection and maintenance}

The animals used in this study were collected using SCUBA equipment during their reproductive season, between April and May of 2012, in the shallow coral reefs (2-7 m depth) in the vicinity of the Sesoko Station of the University of the Ryukyus, Okinawa, Japan $\left(26^{\circ} 38^{\prime} \mathrm{N}, 127^{\circ} 52^{\prime} \mathrm{E}\right)$. Collected animals were kept individually in a perforated small plastic case sunk in a seawater tank. The tank was submerged in running seawater and aerated. We did not feed the nudibranchs, as their food consumption decreases substantially during their reproductive season (Thompson 1966).

\section{Repeated copulation experiment}

We designated five copulatory groups, each consisting of four individuals, and put two individuals into a clear, acrylic frame experimental tank measuring $27 \times 9 \times 6 \mathrm{~cm}$ (length, breadth, height: $1458 \mathrm{ml}$ ) for copulation. The other pair of each group was also permitted to copulate. The mating trials were performed 3 times per animal with each of three different partners within the mating group, with an interval of 2-3 days between each mating trial. We observed a total of 30 copulations. After each copulation, animals were kept individually in small plastic cases until the next trial, and the seawater in the experimental tank was replaced to prevent sperm contamination. We succeeded in collecting 36 out 
of the 40 sperm mass samples after the second and third copulations. We graded the amount of sperm attached to the autotomized penis into three ranks (Fig. 1a), collected each sperm mass with tweezers, and preserved them in $90 \%$ ethanol. We also cut off a part of the mantle (approximately $20 \mathrm{mg}$ ) of each individual and preserved it in $90 \%$ ethanol, after all of the copulation trials.

\section{DNA analysis}

We compared the genotypes of sperm donors and recipients and alleles of sperm samples with six microsatellite markers: sara 10,18, 20,44, 45, and 59 (Sato et al. 2011). We extracted DNA from the mantle of each adult animal and from each sperm mass following the Sato et al. (2011) method. We identified the alleles of the six microsatellite markers in the DNA samples (Sato et al. 2011) using a 3130 Genetic Analyzer (Applied Biosystems) and Gene Mapper 4.0 (Applied Biosystems), and used CERVUS 3.0 (Kalinowski et al. 2007) to calculate the observed and expected heterozygosities and null allele frequencies. When all the donor's alleles were found in a sperm mass in all of the six markers, these alleles were judged to be derived from the donor (D). When all the recipient's alleles were found in a sperm mass, these alleles were judged to be derived from the recipient ( $R$ ). If the alleles do not correspond to the alleles of the recipient or donor, they are possibly derived from the sperms of the recipient's previous

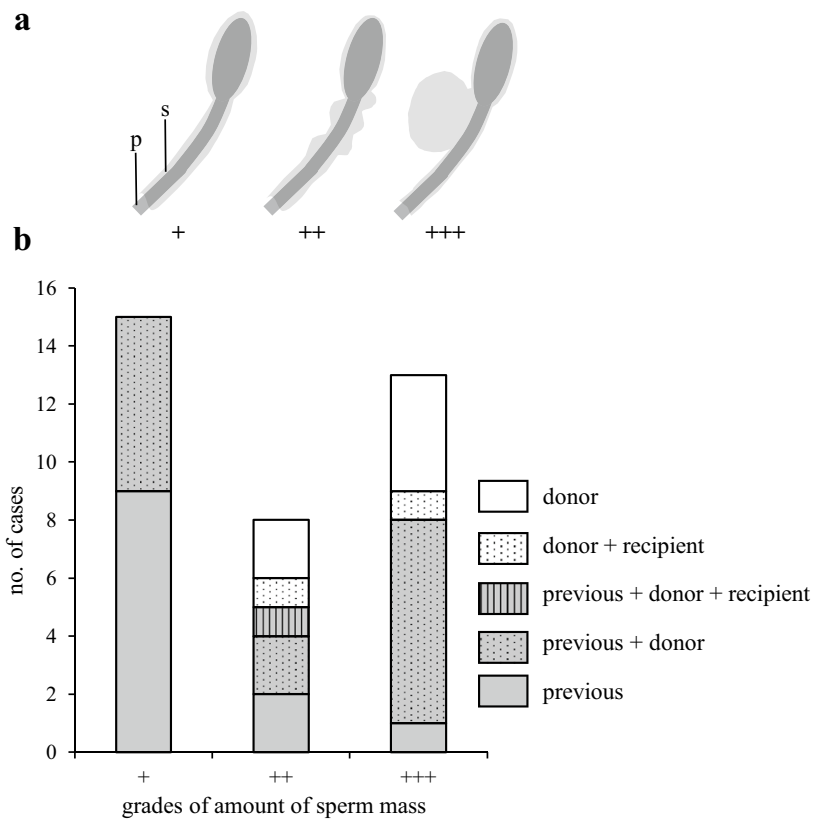

Fig. 1 Amount and origin of sperm mass attached to an autotomized penis after copulation. a Schematic presentation of three grades of the amount of sperm mass. $p$ penis, $s$ sperm mass. b Detected allele patterns in each sperm mass. "Previous" indicates the sperm mass contained allele ${ }^{\mathrm{E}}$ or allele ${ }^{\mathrm{W}}$ (see Table 2) mating partner(s). Among them, we classified the same alleles as those detected from experimentally copulated individuals (recipient's ex-partner or ex-ex-partner) as E alleles, and those alleles not detected from all four individuals within each experimental group as $\mathrm{W}$ alleles. $\mathrm{W}$ alleles have a possibility of being derived from individuals with which the study animals copulated in the wild before capture. In case only some but not all the alleles of the donor/recipient were detected, these were not assigned to either D, R, E, or W alleles.

\section{Results}

We identified the alleles of the sperm mass attached to the backward-pointing spines on the surface of autotomized penises after the second and third copulations of the repeated copulation experiments. We also identified the alleles of the sperm donor and recipient, respectively. The number of alleles, observed and expected heterozygosities, and null allele frequencies of the donors and recipients are shown in Table 1. Negative values for the null allele frequency estimates imply that the observed heterozygote genotype exceeded the statistical expectation (Marshall et al. 1998). Six microsatellite markers successfully distinguished each individual from the others.

It is noteworthy that the number of alleles detected in the sperm samples was generally larger than that detected in the donors and recipients (Table 1). Moreover, we detected three or more alleles in each locus from each of the sperm samples (Table 2). That is, the sperm mass was a mixture of sperm from multiple individuals. In 24 samples, the same alleles as the donor were detected at all of six loci used in the experiments, and thus, the alleles were possibly derived from the donor (Table 2). Similarly, the same alleles as the recipient were detected in three samples, and thus, the alleles were possibly derived from the recipient (Table 2). In 21 samples, the same alleles as the ex- or ex-ex-partner were detected at some, but not all of the six loci (allele ${ }^{\mathrm{E}}$, Table 2). For example, the sperm mass sample of Fsp2 was collected from the penis of individual $\mathrm{F}$ after the second copulation trial. In this second copulation trial, F's mating partner was B that had copulated with A in the first copulation trial. Therefore, there is some possibility that $\mathrm{B}$ received and stored sperm from A in its allo-sperm storage organs in the first copulation trial, and then $\mathrm{F}$ removed the sperm originally from $\mathrm{A}$ from B's allo-sperm storage organs in the second copulation trial. We assumed that allele 149 in locus sara 20 of 'Fsp2' originated from $\mathrm{A}$ and thus indicated it as allele ${ }^{\mathrm{E}}$ (previously copulated individual). However, it is also possible that the allele is derived from an unknown wild individual. Therefore, we could not specify the origin of the sperm. In 23 samples, some alleles were not identical with any alleles of individuals of the experimental group. We thought that those 
Table 1 Characterization of six microsatellite loci from Chromodoris reticulata

\begin{tabular}{|c|c|c|c|c|c|}
\hline Locus & $\begin{array}{l}\text { Individuals }(n=20) \\
\text { Sperm masses }(n=36)\end{array}$ & No. of alleles & $H_{\mathrm{O}}$ & $H_{\mathrm{E}}$ & $\begin{array}{l}\text { Null allele } \\
\text { frequency }\end{array}$ \\
\hline \multirow[t]{2}{*}{ saralo } & Individuals & 9 & 0.850 & 0.860 & -0.008 \\
\hline & Sperm masses & 11 & & & \\
\hline \multirow[t]{2}{*}{ saral8 } & Individuals & 19 & 0.650 & 0.958 & 0.179 \\
\hline & Sperm masses & 21 & & & \\
\hline \multirow[t]{2}{*}{ sara20 } & Individuals & 18 & 0.750 & 0.947 & 0.102 \\
\hline & Sperm masses & 20 & & & \\
\hline \multirow[t]{2}{*}{ sara44 } & Individuals & 22 & 0.450 & 0.972 & 0.355 \\
\hline & Sperm masses & 23 & & & \\
\hline \multirow[t]{2}{*}{ sara45 } & Individuals $(n=19)^{\mathrm{a}}$ & 17 & 0.474 & 0.954 & 0.327 \\
\hline & Sperm masses & 18 & & & \\
\hline \multirow[t]{2}{*}{ sara59 } & Individuals & 5 & 0.350 & 0.579 & 0.249 \\
\hline & Sperm masses & 5 & & & \\
\hline
\end{tabular}

CERVUS 3.0 (Kalinowski et al. 2007) was used to calculate the observed and expected heterozygosities and null allele frequencies. Negative values for null allele frequency estimates imply an observed heterozygote genotype in excess of statistical expectation (Marshall et al. 1998)

$H_{\mathrm{O}}$ observed heterozygosity, $H_{\mathrm{E}}$ expected heterozygosity of individuals

${ }^{\mathrm{a}}$ In the locus of sara45, we could analyse only 19 samples samples with alleles different from the donor or the recipient had a possibility of originating from the recipient's previous partner prior to collection (allele ${ }^{\mathrm{W}}$, Table 2).

In the results of the genotype and allele comparison of sperm masses, donors and recipients, alleles from neither donors nor recipients were detected in 28 sperm masses [sperm masses including alleles of the recipient's previous partner(s) only (previous), $n=12$; alleles of recipient's previous partner(s) and alleles of donor, $n=15$ (donor + previous); alleles of the recipient's previous partner(s) and alleles of donor and recipient (donor + recipient + previous), $n=1$; Table 2]. By contrast, the alleles of the recipient's previous partner(s) were not detected in eight sperm masses [sperm mass including alleles of donor only (donor), $n=6$, donor and recipient (donor + recipient), $n=2$; Table 2].

Some samples contained sperm of the recipient's previous partner(s), irrespective of the grade of the amount of sperm attached to the autotomized penis ( $n=28$, Fig. 1 b). Sperm from the recipient's previous partner(s) was detected from all the sperm mass samples of grade ' + ' $(n=15$, Fig. 1b). Some sperm mass samples of grade ' ++ ' and ' +++ ' did not contain sperm of the recipient's previous partner(s) $(n=8$, Fig. 1b). All of the samples that lacked the sperm of the recipient's previous partner(s) contained the sperm of the donor.

\section{Discussion}

In this study, we obtained the first proof of sperm removal from the reproductive or copulatory organ by DNA analysis of scraped-out sperm. In 28 out of the 36 samples of sperm mass attached to the autotomized penis, we detected alleles that originated from the recipient's previous partner(s) (Fig. 1) This result demonstrates sperm removal in C. reticulata, in which allo-sperm already stored in the reproductive pouch(s) of a mating partner was scraped out using the thorny penis. It is well known that some damselflies remove sperm from the copulatory pouch of mating partners (Córdoba-Aguilar et al. 2003). However, sperm displacement in damselflies was evaluated based on increases and decreases in the amount of stored sperm (Córdoba-Aguilar et al. 2003). Direct evidence of sperm removal by DNA analysis of scraped-out sperm has not yet been shown in animals reported to perform sperm displacement (Kamimura 2005).

The manner of sperm removal in C. reticulata differed from that in damselflies. Some damselflies such as Calopteryx maculata are known to use a hook-shaped structure at the tip of the appendage of male copulatory organ to remove allo-sperm already stored in the copulatory pouch (Waage 1979; Cordero and Miller 1992; Miller 1987). Damselflies removed allo-sperm with a voluntary movement by the tergo-sternal muscle that is associated with a hook-shaped appendage (Córdoba-Aguilar et al. 2003). Unlike the hookshaped appendage in damselflies, the disposable penis in C. reticulata does not have a retractor muscle (Sekizawa et al. 2013), so it appears impossible to move each spine in a controlled manner. It is plausible that they insert their penis deeply into the copulatory pouch of the mating partner, and ejaculate their own sperm at the innermost part, then entangle allo-sperm with backward-pointing spines on the swollen tip of the penis, pull out the penis entangled with allo-sperm, and finally autotomize the penis after copulation. 


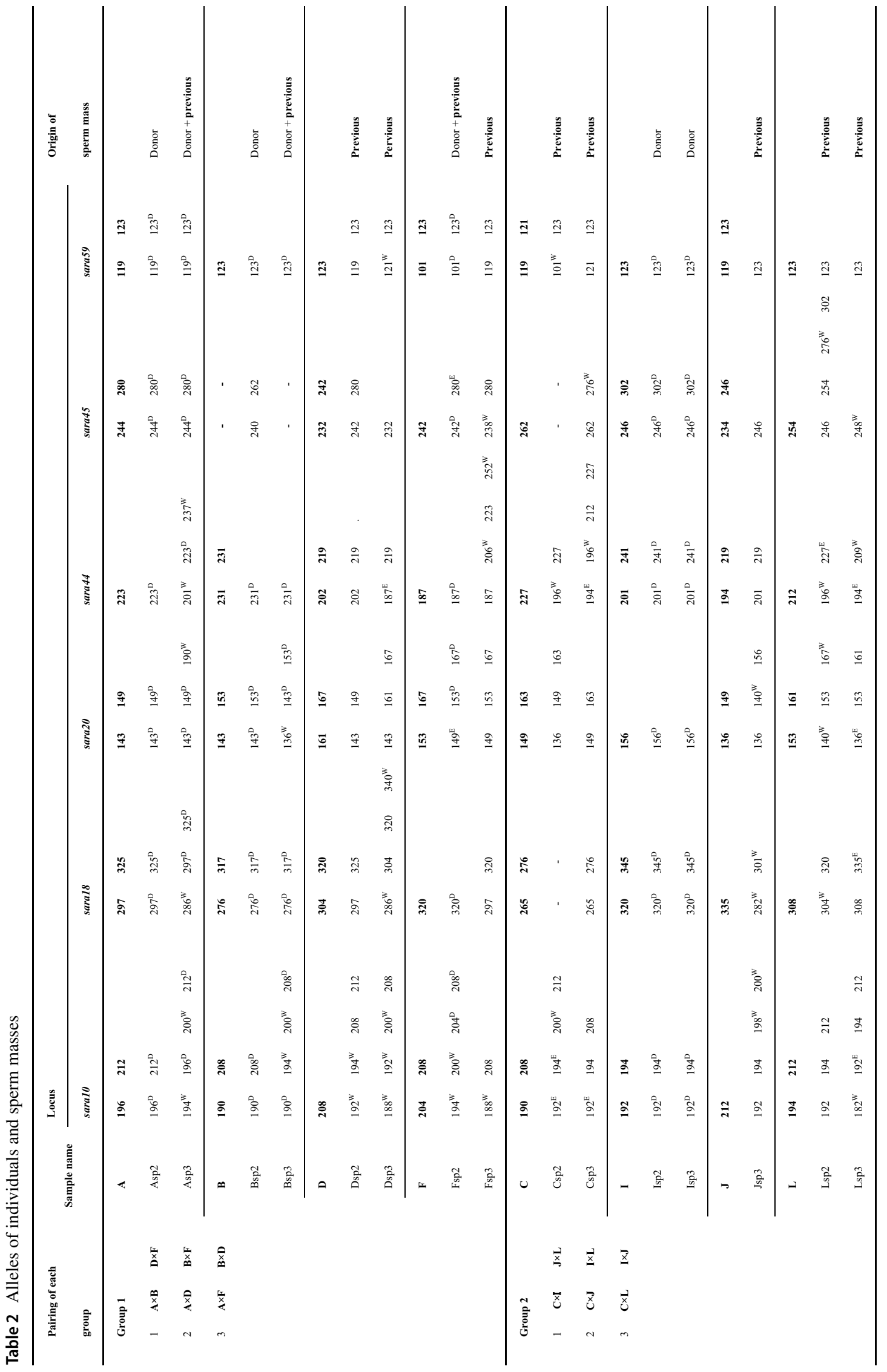




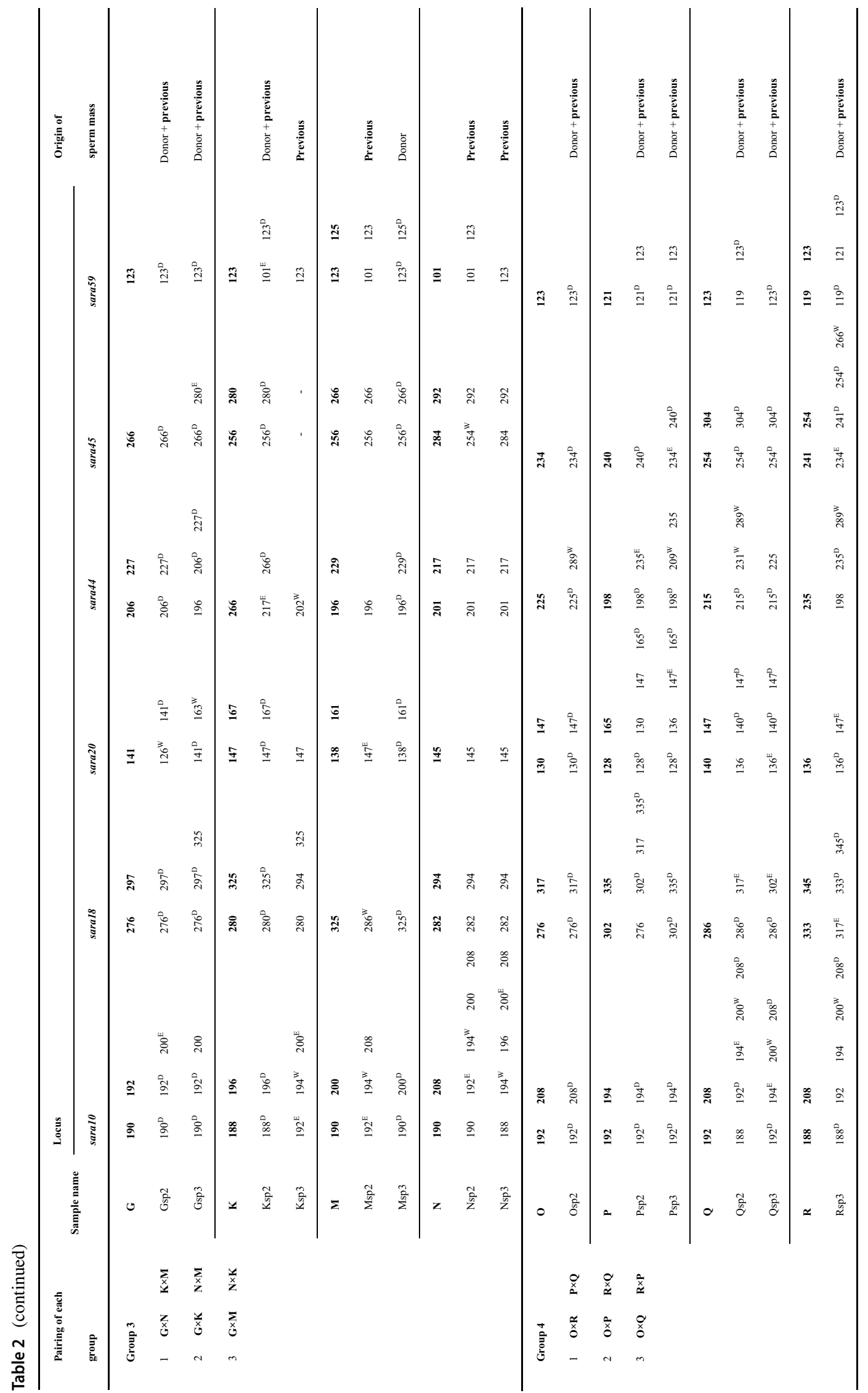




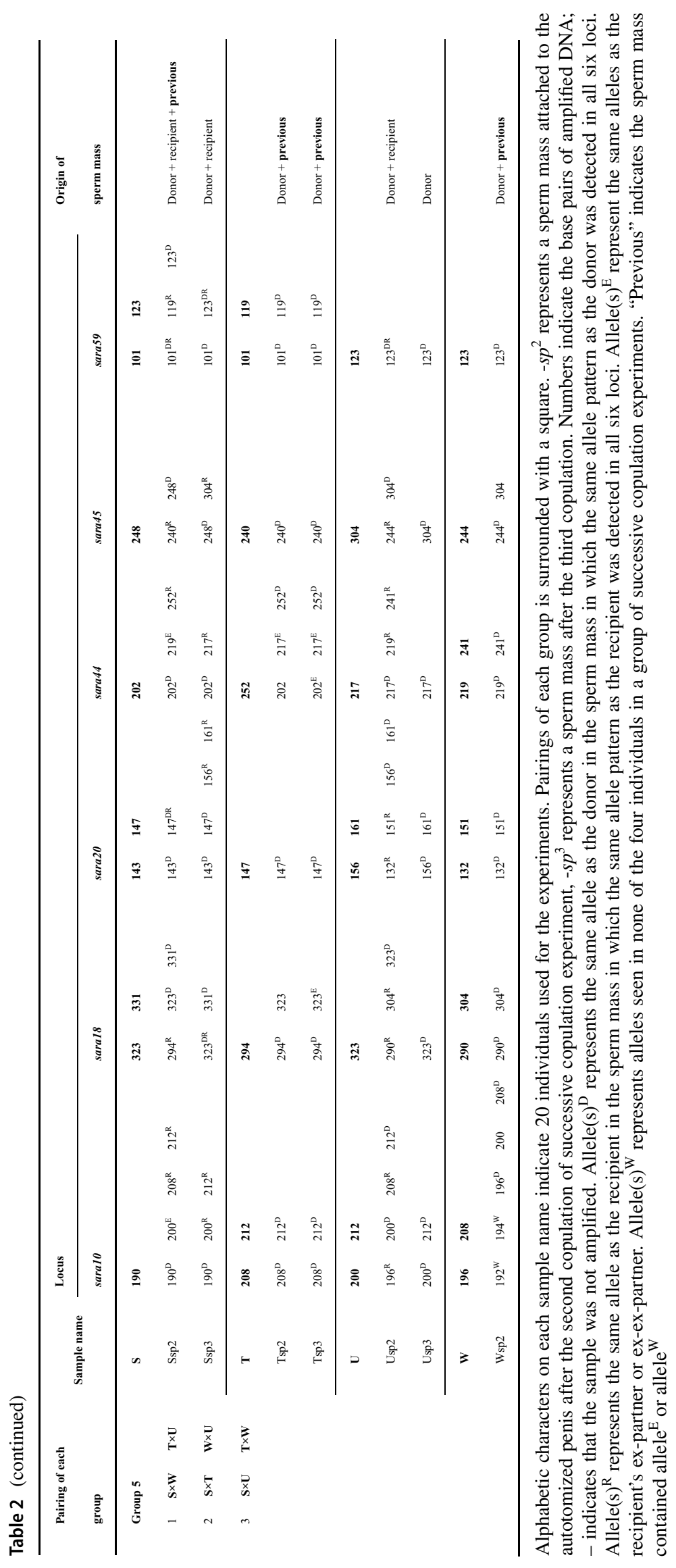


No alleles of the recipient's previous partner(s) detected in the removed sperm mass was coincident with that of the recipient's ex- or ex-ex-partner used in the mating experiments in all six loci. Alleles that did not match with any of the four individuals in each group were detected from 23 sperm masses (allele ${ }^{\mathrm{W}}$, Table 2 ). This suggests that $C$. reticulata removed sperm originating from the mating partner(s) of preceding copulations that occurred in the wild prior to collection. There are a few possible reasons why the same alleles as the recipient's ex- and ex-ex-partner were not detected from the removed sperm mass. The primary possibility is that the amount of sperm originating from the ex- and ex-ex-partner was too little to detect the same alleles at all of the six loci necessary to determine genotype, because the detection sensitivity of alleles varied among markers (loci). The other possibility is that the amount of the sperm of the recipient's ex- and ex-ex-partner was greatly reduced in (the removable area of) the copulatory pouches of the sperm recipient at the time of fixation, owing to sperm movement and transport, or sperm digestion in the copulatory pouches. The sperm of the recipient's previous partner(s) was detected from some sperm mass samples of each grade of the amount of sperm. This shows that sperm displacement succeeded irrespective of the amount of sperm attached to the autotomized penis. Some sperm mass samples of grade ' ++ ' and ' +++ ' did not contain sperm of the recipient's previous partner(s) but sperm of the donor itself. In these cases, the sperm donor may ejaculate in an inappropriate place (for example the diverticulums connecting the copulatory bursa and seminal receptacle) before inserting its penis into the correct position. This may cause the attachment of auto-sperm to the surface of the penis to prevent it from scraping out allo-sperm. There are possible causes for the detection of the DNA of the recipient from the sample of sperm mass: (1) cells of the recipient's female reproductive organ were scraped and attached to the penis of the sperm donor at copulation, (2) sperm that leaked out from the penis of the recipient was attached to the penis of the donor when both partners pulled out their respective penises at the end of copulation.

C. reticulata autotomizes its penis after every copulation (Sekizawa et al. 2013) and it is thought that the autotomy of the penis evolved to remove allo-sperm from the mating partner efficiently. We clarified in this study that sperm donors removed allo-sperm already stored in the copulatory pouch(es) of sperm recipients with backward-pointing spines on the penis as the final process of their copulation. Though a long and thorny penis is advantageous in scraping out allo-sperm at copulation, such a penis is difficult to pull back into the body again after copulation. And the backward-pointing spines on the penis covered with sperm at copulation will not remove allo-sperm efficiently at the next copulation, like a Velcro ${ }^{\mathrm{TM}}$ tape. Such morphological and functional inconveniency may have made $C$. reticulata develop a cheap and fragile penis and dispose of it, rather than a robust but expensive one and reuse it.

The mating behaviour of $C$. reticulata suggests that sexual selection functions intensely in simultaneous hermaphrodites. In $C$. reticulata, we clarified that sperm donors removed allo-sperm stored from a third or more preceding copulation, and that sperm originating from 2 or more individuals was stored in the seminal receptacle of recipients. The ability to displace allo-sperm with a thorny penis and the ability to copulate repeatedly at intervals of $24 \mathrm{~h}$ by rapid replenishment of the disposed penis (Sekizawa et al. 2013) in $C$. reticulata suggest that competition to fertilize is quite intense and mating frequency in the wild is not so low in this species. As the disposable penis in $C$. reticulata has a similar function as the accessory structure of the copulatory organ of damselflies, we suppose that sexual selection may work as intensely in simultaneously hermaphroditic animals as it does in gonochorists. Additionally, we propose that the low-density model, which states that simultaneous hermaphroditism evolved to fully utilize scarce mating opportunities caused by low density or low mobility (Ghiselin 1969), should be re-evaluated, at least in the case of $C$. reticulata.

Acknowledgements We are grateful to K. Sakai of the Sesoko Station of the University of Ryukyus, for his help during the field survey in Okinawa. We are also thankful to A. Shimizu and M. Okubo of the National Research Institute of Fisheries Science, Fisheries Research; N. Sato of Shimane University; and S. Nanami of Osaka City University, for their help performing DNA analysis. We thank S. Shiga for her help and encouragement. This work was financially supported by a Grantin-Aid (\#22570029) for Scientific Research to Y. N. from the Japanese Ministry of Education, Culture, Sports, Science and Technology.

\section{Compliance with ethical standards}

Conflict of interest The authors declare that they have no conflict of interest.

Ethical approval This article does not contain any studies with human participants performed by any of the authors. All applicable international, national, and/or institutional guidelines for the care and use of animals were followed.

Informed consent Irrelevant.

Open Access This article is licensed under a Creative Commons Attribution 4.0 International License, which permits use, sharing, adaptation, distribution and reproduction in any medium or format, as long as you give appropriate credit to the original author(s) and the source, provide a link to the Creative Commons licence, and indicate if changes were made.

The images or other third party material in this article are included in the article's Creative Commons licence, unless indicated otherwise in a credit line to the material. If material is not included in the article's Creative Commons licence and your intended use is not permitted by statutory regulation or exceeds the permitted use, you will need to obtain permission directly from the copyright holder.

To view a copy of this licence, visit http://creativecommons.org/ licenses/by/4.0/. 


\section{References}

Angeloni L, Bradbury JW, Burton RS (2003) Multiple mating, paternity, and body size in a simultaneous hermaphrodite, Aplysia californica. Behav Ecol 14(4):554-560

Baur B (1994) Multiple paternity and individual variation in sperm precedence in the simultaneously hermaphroditic land snail Arianta arbustorum. Behav Ecol Sociobiol 35(6):413-421

Baur B (1998) Sperm competition in molluscs. In: Birkhead TR, Møller AP (eds) Sperm competition and sexual selection. Academic Press, London, pp 255-305

Brandriff B, Beemen RD (1973) Observations on the gametolytic gland in the anaspidean opisthobranchs, Phyllaplysia taylori and Aplysia californica. J Morphol 141:395-409

Cooper G, Miller P, Holland PWH (1996) Molecular genetic analysis of sperm competition in the damselfly Ischnura elegans (Vader Linden). Proc R Soc Lond B 263:1343-1349

Cordero A, Miller PL (1992) Sperm transfer, displacement and precedence in Ischnura graellsii (Odonata: Coenagrionidae). Behav Ecol Sociobiol 30:261-267

Córdoba-Aguilar A, Uhía E, Rivera AC (2003) Sperm competition in Odonata (Insecta): the evolution of female sperm storage and rivals' sperm displacement. J Zool 261:381-398

Dillen L, Jordaens K, Backeljau T (2009) Sperm transfer, sperm storage, and sperm digestion in the hermaphroditic land snail Succinea putris (Gastropoda, Pulmonata). Invertebr Biol 128:97-106

Evanno G, Madec L, Arnaud J (2005) Multiple paternity and postcopulatory sexual selection in a hermaphrodite: what influences sperm precedence in the garden snail Helix aspersa? Mol Ecol 14(3):805-812

Fischer EA (1980) The relationship between mating system and simultaneous hermaphroditism in the coral reef fish Hypoplectrus nigricans (Serranidae). J Anim Behav 28:620-633

Fischer EA (1981) Sexual allocation in a simultaneously hermaphroditic coral reef fish. Am Nat 177:64-82

Ghiselin MT (1969) The evolution of hermaphroditism among animals. Q Rev Biol 44:189-208

Gosliner TM, Behrens DW, Valdés Á (2008) Indo-Pacific nudibranchs and sea slugs: a field guide to the world's most diverse fauna. Sea Challengers Natural History Books, Washington, p 426

Kalinowski ST, Taper ML, Marshall TC (2007) Revising how the computer program CERVUS accommodates genotyping error increases success in paternity assignment. Mol Ecol 16:1099-1106

Kamimura Y (2000) Possible removal of rival sperm by the elongated genitalia of the earwig, Euborella plebeja. Zool Sci 17:667-672

Kamimura Y (2003) Effects of broken male intromittent organ on the sperm storage capacity of female earwig, Euborella plebeja. J Ethol 21:29-35

Kamimura Y (2005) Last-male paternity of Euborella plebeja, an earwig with elongated genitalia and sperm-removal behavior. J Ethol 23:35-41
Kupfernagel S, Rusterholz H, Baur B (2010) Variation in multiple paternity and sperm utilization patterns in natural populations of a simultaneous hermaphrodite land snail. Biol J Linn Soc 99(2):350-361

Lange R, Werminghausen J, Anthes N (2013) Does traumatic secretion transfer manipulate mating roles or reproductive output in hermaphroditic sea slug? Behav Ecol Sociobiol 67:1239-1247

Lange R, Werminghausen J, Anthes N (2014) Cephalo-traumatic secretion transfer in a hermaphrodite sea slug. Proc R Soc B 281: 20132424. https://doi.org/10.1098/rspb.2013.2424

Leonard J, Westfall J, Pearse J (2007) Phally polymorphism and reproductive biology in Ariolimax (Ariolimax) buttoni (Pilsbry and Vanatta, 1896) (Stylommatophora: Arionidae). Am Malacol Bull 23:121-135

Lind H (1973) The functional significance of the spermatophore and the fate of spermatozoa in the genital tract of Helix pomatia (Gastropoda: Stylommatophora). J Zool 169:39-64

Marshall TC, Slate J, Kruuk LEB, Pemberton JM (1998) Statistical confidence for likelihood-based paternity inference in natural populations. Mol Ecol 7:639-655

Michiels NK (1998) Mating conflicts and sperm competition in simultaneous hermaphrodites. In: Birkhead TR, Møller AP (eds) Sperm competition and sexual selection. Academic Press, London, pp 219-254

Michiels NK, Newman LJ (1998) Sex and violence in hermaphrodites. Nature 391:647

Miller PL (1987) Sperm competition in Ischnura elegans (Vander Linden) (Zygoptera: Coenagrionidae). Odonatologica 16:201-207

Rudman WB (1984) The Chromodorididae (Opisthobranchia: Mollusca) of the Indo-West Pacific: a review of the genera. Zool J Linn Soc Lond 81:115-273

Sato N, Sekizawa A, Awata S, Munehara H, Nakashima Y (2011) Isolation and characterization of microsatellite markers in the nudibranch Chromodoris tinctoria. Venus 69:214-217

Sekizawa A, Seki S, Tokuzato M, Shiga S, Nakashima Y (2013) Disposable penis and its replenishment in a simultaneous hermaphrodite. Biol Lett 9:20121150. https://doi.org/10.1098/rsbl.2012.1150

Siva-Jothy MT, Hooper R (1995) The disposition and genetic diversity of stored sperm in the damselfly Calopteryx splendens xanthostoma (Charpentier). Proc R Soc Lond B 259:313-318

Takami Y (2007) Spermatophore displacement and male fertilization success in the ground beetle Carabus insulicola. Behav Ecol 18(3):628-634

Thompson TE (1966) Studies on the reproduction of Archidoris pseudoargus (Rapp) (Gastropoda Opisthobranchia). Phil Trans R Soc Lond B 343:343-374

Valdés Á, Gosliner TM, Ghiselin MT (2010) Opisthobranchs. In: Leonard J, Cordoba-aguilar A (eds) The evolution of primary sexual characters in animals. Oxford University, UK, pp 148-172

Waage JK (1979) Dual function of the damselfly penis: sperm removal and transfer. Science 203:916-918 